\title{
BMJ Open Return to work following unintentional injury: a prospective follow-up study
}

\author{
Urs Hepp, ${ }^{1}$ Ulrich Schnyder, ${ }^{2}$ Sofia Hepp-Beg, ${ }^{3}$ Josefina Friedrich-Perez, ${ }^{4}$ \\ Niklaus Stulz, ${ }^{1}$ Hanspeter Moergeli ${ }^{2}$
}

To cite: Hepp U, Schnyder U, Hepp-Beg S, et al. Return to work following unintentional injury: a prospective followup study. BMJ Open 2013;3: e003635. doi:10.1136/ bmjopen-2013-003635

- Prepublication history for this paper is available online. To view these files please visit the journal online (http://dx.doi.org/10.1136/ bmjopen-2013-003635).

Received 22 July 2013 Revised 13 November 2013 Accepted 14 November 2013

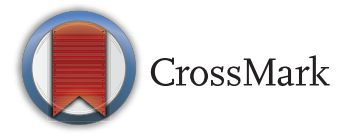

${ }^{1}$ Outpatient Department, Psychiatric Services Aargau (Teaching Hospital of the University of Zurich), Brugg, Switzerland

${ }^{2}$ Department of Psychiatry and Psychotherapy, University Hospital Zurich, Zurich, Switzerland

${ }^{3}$ Private Practice, Zurich, Switzerland

${ }^{4}$ Hospital Männedorf AG, Männedorf, Switzerland

Correspondence to Dr Urs Hepp; urs.hepp@pdag.ch

\section{ABSTRACT}

Objective: The aim of this study was to predict time off work following unintentional injuries due to accidents leading to hospital admission.

Design: Prospective 6-month follow-up study. Setting: Department of Trauma Surgery of a University Hospital.

Participants: Consecutively recruited victims of unintentional injuries $(n=221)$ hospitalised for a minimum of $32 \mathrm{~h}$ including two consecutive nights. All the participants were aged 18-65 years and were able to participate in an assessment within 30 days of the accident.

Main outcome measures: Interview-assessed number of days off work during the 6 months immediately following the accident.

Results: The patients' subjective appraisals of (1) accident severity and (2) their ability to cope with the resulting injury and its job-related consequences predicted time off work following the accident beyond the impact of the objective severity of their injury and the type of accident involved.

Conclusions: The patients' subjective appraisals of the accident severity and of their ability to cope with its consequences are highly relevant for return to work after accidents. Extending the findings from previous studies on severely injured and otherwise preselected accident victims, this seems to apply to the whole spectrum of patients hospitalised with unintentional injuries.

\section{INTRODUCTION}

In the European Union (EU) every year 6.5 million people are admitted to hospitals following unintentional injuries due to accidents. ${ }^{1}$ This figure corresponds to more than $1 \%$ of the 500 million inhabitants in the EU. In addition to the direct costs of the treatment, unintentional injuries cause even higher indirect costs. Sick leave following unintentional injuries is one of the most important contributors to these indirect costs. ${ }^{2}{ }^{3}$ Return to work is one of the most relevant measures of functional outcome of injuries, ${ }^{4}$ and there is a growing body of literature on return to work after chronic
Strengths and limitations of this study

- The application of very few exclusion criteria may have strengthened the study's external validity (generalisability), but at the same time may have limited its internal validity (ie, factors other than the unintentional, accident-related injury might have influenced time off work).

- There were $68(23.5 \%)$ dropouts from baseline to follow-up, which, however, did not differ from the completers with respect to available patient and accident-related characteristics.

- Sick leave after unintentional injuries due to accidents was assessed in terms of time off work during the follow-up period, which provided a more accurate estimation of work-related consequences of accidents than the mere assessment whether the accident victim had returned to work or not at a particular point in time.

- However, the number of days off work was assessed by means of self-reports by the patients due to strict data privacy protection laws in Switzerland.

injuries such as low-back pain. ${ }^{5}$ However, there are still relatively few studies on return to work after unintentional injuries due to accidents. $^{26-14}$

Generally, return to work is not only predicted by injury-related or medical factors. Job-related factors, ${ }^{2} 12 \quad 15 \quad 16$ socioeconomic factors, ${ }^{2} 791217$ psychological distress, ${ }^{9}{ }^{11} 12$ causal attribution ${ }^{18}$ and compensation eligibility ${ }^{10}{ }^{19}$ become increasingly important factors for return to work the longer the medical condition lasts. How patients' expectations of recovery affect their health and vocational outcome is insufficiently researched. ${ }^{20}{ }^{21}$ Compared with those remaining on sick leave, patients returning to work after injury had stronger internal health beliefs, that is, they believed that they had an influence on their own health and considered themselves powerful. ${ }^{7}$ In several studies involving various medical conditions, patients' own expectations and predictions of their future work ability predicted return to work. ${ }^{22-24}$ There are relatively few studies examining the role of the 
subjectively experienced accident severity and the subjectively experienced ability to cope with the unintentional injury regarding return to work. ${ }^{7-9} 1325$ The findings from these studies cannot be generalised as they are compromised by their highly selective samples: the studies were either restricted to severely injured patients without preexisting mental disorders, ${ }^{7} 81326$ and/or they excluded foreign-language patients. ${ }^{7} 81213192627$ In a previous study of severely injured accident victims, we found that time off work was best predicted by the patients' own appraisals of accident severity and by the patients' own expectations regarding their ability to cope with the unintentional injury and its job-related consequences. ${ }^{13}$ While at the 1-year follow-up, injury severity measured by the Injury Severity Score (ISS) ${ }^{28}$ and type of accident (traffic, workplace or sporting/leisure) were also predictive of time off work, ${ }^{8}$ at the 3-year follow-up, only the self-reported appraisals of accident severity and the patients' ability to cope with the unintentional injury remained predictive of days absent from the workplace. ${ }^{13}$ However, the sample in this previous study was highly selective. We included only severely injured (ISS $\geq 10$ ), German-speaking patients and excluded patients who had been under treatment for any mental disorders and/or serious somatic illnesses at the time of the accident. By doing this we may have excluded patients at a higher risk for sick leave and the results may therefore not be generalised to apply to all accident survivors.

The aim of this study was to predict time off work (ie, the number of sick leave days) during the first 6 months following unintentional, accident-related injuries in an independent, larger and less selective sample of patients with any unintentional injury requiring hospital admission.

\section{METHODS}

\section{Sample}

Participants were recruited from the Department of Trauma Surgery at the Zurich University Hospital. All the patients qualifying for the study had sustained unintentional injuries that required hospitalisation for a minimum of $32 \mathrm{~h}$ including two consecutive nights (the latter guaranteed exclusion of patients who were treated in the emergency room overnight but who were not really hospitalised on a ward of the Department of Trauma Surgery). Further inclusion criteria were: age between 18 and 65 years; ability to participate in an extensive assessment within 30 days of the accident; and sufficient proficiency in one of the study languages (German, Italian, Spanish, Portuguese, Serbo-Croatian, Turkish or Albanian) to participate in the interview and to complete the self-report questionnaires. Non-German speaking participants were assessed using interpreters and professionally translated psychometric instruments. Exclusion criteria were: a Glasgow Coma Scale (GCS) score $^{29}$ below 9; unconsciousness for more than $15 \mathrm{~min}$ after the accident; pathological findings in the cranial CT; and attempted suicide.

In contrast to our previous study, ${ }^{8} 13$ neither serious somatic illness nor being in treatment for a mental disorder prior to the accident was an exclusion criterion in the present study. ${ }^{30}$ Note that the sample of the previous study $^{8} 13$ and the sample of the present study on time off work were completely independent from each other (recruitment of the second sample started 18 months after the end of recruitment for the first sample). With regard to the possibility of generalising the present study's findings, we also retained the patients for the present study who showed marked clinical signs or symptoms of mental disorders that were obviously unrelated to the unintentional injury.

Patients were recruited over a period of 12 months. During this time period 787 patients aged between 18 and 65 years were admitted with unintentional injuries. Of these patients, $253 \mathrm{did}$ not meet the inclusion criteria due to early discharge $(104 ; 41.1 \%)$, poor clinical condition $(74 ; 29.2 \%)$, GCS score below 9 (46; 18.2\%), insufficient proficiency in one of the study languages (21; $8.3 \%)$ or other reasons $(29 ; 11.5 \%)$ (multiple reasons possible). As a result, 534 patients fulfilled all criteria and were eligible for the study. Owing to a restricted interviewing capacity, not all the eligible patients could be assessed. The following procedure was applied to ensure the recruitment of a representative sample and to control for potential bias attributable to the time of admission: on day 1, every other consecutive patient (ie, patient $1,3,5$, etc) was interviewed. On day 2 , the order of the list of admissions was reversed, so that the last patient admitted was interviewed first, the third last patient was interviewed second and so forth. On day 3, the order was reversed again, etc. The 148 patients who could not be contacted due to our limited interviewing capacity did not differ from the participating patients with regard to age (mean difference $=-0.40$ years, $95 \%$ CI -2.93 to $2.12, \mathrm{t}=-0.31, \mathrm{df}=481 ; \mathrm{p}=0.754)$ and gender (Pearson's $\chi^{2}=0.77, \mathrm{df}=1 ; \mathrm{p}=0.375$ ). Of the 386 patients who were contacted, 335 gave their written consent to participate. The $51(13.2 \%)$ patients who declined participation did not differ significantly from the participating patients with regard to age (mean difference $=3.75$ years, $95 \%$ CI -0.12 to $7.61, \mathrm{t}=-1.91$, $\mathrm{df}=384 ; \mathrm{p}=0.057$ ) and gender (Pearson's $\chi^{2}=0.07, \mathrm{df}=1$; $\mathrm{p}=0.792$ ).

After the exclusion of a small number of victims of physical violence $(n=12)$, the sample consisted of 323 patients who all attended the interview at T1. On an average, the $\mathrm{T} 1$ interview was performed 5 days after the referral to the hospital (SD 4.2 days; range 2-28 days). Thirty-four patients had no regular work and were excluded from further analyses regarding time off work. However, four patients who were receiving unemployment compensation at the time of the accident were retained for further analyses. For these patients, accident-related time off work was traceable since they 
needed a doctor's certificate to continue to be eligible for unemployment compensation. In all, valid data regarding time off work were obtainable from 289 patients.

On an average, the follow-up interview (T2) took place 188 (SD 16.2; range 155-257) days after the unintentional injury. Sixty-eight (23.5\%) dropped out during the follow-up period; these 68 dropouts did not differ significantly from the final sample with regard to age (mean difference $=-2.78$ years, $95 \%$ CI -6.13 to $0.57, \mathrm{t}=-1.63$, $\mathrm{df}=287 ; \quad \mathrm{p}=0.104)$, gender (Pearson's $\chi^{2}=3.3, \quad \mathrm{df}=1$; $\mathrm{p}=0.069$ ), type of accident (Pearson's $\chi^{2}=6.5, \mathrm{df}=1$; $\mathrm{p}=0.088$ ), clinician-rated $\mathrm{ISS}^{28}$ (mean difference $=-0.77$, $95 \%$ CI -3.54 to $1.99, \mathrm{t}=-0.55, \mathrm{df}=287 ; \mathrm{p}=0.582)$, patient-rated subjective accident severity $(\mathrm{t}=1.19, \mathrm{df}=287$; $\mathrm{p}=0.237$ ), appraisal of coping abilities (mean difference $=$ $-0.16,95 \%$ CI -0.37 to $0.04, \mathrm{t}=-1.58, \mathrm{df}=283 ; \mathrm{p}=0.115)$ and intrusions as measured by the Impact of Event Scale $\left(\right.$ IES) ${ }^{31}$ (mean difference $=0.87,95 \%$ CI -1.14 to 2.28 , $\mathrm{t}=0.86, \mathrm{df}=276 ; \mathrm{p}=0.393)$. The final sample consisted of 221 patients.

\section{Measures}

The ISS $^{28}$ and the $\mathrm{GCS}^{29}$ were routinely assessed by the surgeons immediately after admission to the emergency room. The ISS permits an evaluation of the severity of injuries by a trauma surgeon: each part or area of the body affected is given a score $(1=$ minimum to $6=$ fatal injury). If the score is 6 in one area, the ISS is assigned a sum score of 75 . Otherwise, the scores for the three most severely injured areas of the body are squared and then summed, producing a maximum score of 75 . Patients with a score of 10 or more are generally considered severely injured. The GCS is an observer-rated scale for the clinical appraisal of the gravity of coma after injury to the skull and brain. Patients with severe traumatic brain injuries generally have a score under 9 .

The semistructured interview at $\mathrm{T} 1$ covered sociodemographic data, a detailed work record and information about the accident. Existing preaccident psychiatric disorders were assessed using the Primary Care Evaluation of Mental Disorders (PRIME-MD) ${ }^{32}$ The patients rated their appraisal of the injury severity on a Likert scale ranging from ' $1=$ very slight' to ' $5=$ very severe'. They also rated their ability to cope with the unintentional injury and its job-related consequences on a Likert scale ranging from ' $1=$ very poor' to ' $5=$ =very good'. 13 Post-traumatic psychological symptoms were assessed by the IES, ${ }^{31}$ a 15 -item self-rating questionnaire comprising two subscales (intrusion and avoidance) with high reliability and validity. ${ }^{33}$ Time off work, assessed at 6 months (T2) postaccident, was defined as the patient-reported number of sick leave days attributable to the unintentional injury and its consequences including time of hospitalisation. To record their sick leave days the patients used a specified journal they received at T1. A week off work was set to equal 7 days of leave. Where patients returned to work on a part-time basis, the days on which they worked less were added to the days of leave on a pro rata basis. ${ }^{13}$ The interviews were performed by two medical doctors (SH-B and JF-P). Each patient was interviewed by the same interviewer at T1 and T2. Detailed information on the study design and the inter-rater reliability is described in an earlier publication on the incidence of post-traumatic stress disorder in that sample. ${ }^{34}$

\section{Statistical analysis}

Hierarchical linear multiple regression analyses were performed to predict the number of sick leave days. They allowed for highlighting the relevance of patient's appraisal among the selected potential predictor variables. To enable us to enter the type of accident (road traffic, workplace, household or leisure-time accidents) as a predictor into the multiple regression analysis, this categorical variable was converted into a set of three new variables so that a deviation contrast resulted. In this way the effect of each accident category was compared with the mean effect of all accident categories. Since there was one new variable for each degree of freedom, one accident category (household) had to be omitted in the regression analysis. In the final regression model including all potential predictors, multicollinearity was low (tolerance $>0.75$ ) and the distribution of regression standardised residuals was normal (Kolmogorov-Smirnov Z=0.63, $\mathrm{p}=0.827$ ). Group comparisons of dimensional variables were performed with $\mathrm{t}$ tests. Written informed consent was obtained from all participants.

\section{RESULTS}

The sociodemographic characteristics are presented in table 1. Thirty-five $(15.8 \%)$ of the 221 patients suffered from one or multiple pre-existing mental disorders immediately prior to the accident, and 31 patients (14\%) did not speak German. The characteristics related to the unintentional injury of the 221 patients are found in table 2. The types of accident were as follows: $72(32.6 \%)$ traffic accidents, $66(29.9 \%)$ workplace accidents, $6(2.7 \%)$ household accidents and 77 (34.8\%) sports/leisure activity-related accidents. The mean ISS differed significantly between the types of accident (traffic: M 16.0, SD 12.4; workplace or household: M 11.8, SD 8.2; sporting/leisure activity: M 8.7, SD 7.7; analysis of variance: $\mathrm{F}=10.7 ; \mathrm{df}=2,218 ; \mathrm{p}<0.001$ ).

According to the surgeons' files, 44 (19.9\%) patients sustained a mild or moderate traumatic brain injury. Forty-one $(18.6 \%)$ patients were first referred to the intensive care unit (ICU), with a mean duration of ICU stay of 4 days (SD 3.7; range 1-19). The mean length of stay at the acute hospital including the ICU was 15.8 days (SD 16.9; range 2-110). Forty-six patients had a further stay in a rehabilitation hospital, with a mean length of stay of 35 days (SD 25.0; range 3-141). The mean number of sick leave days was 95.7 (SD 58.1; range 6-183). The patients suffering from pre-existing 
Table 1 Sociodemographic characteristics of injured accident victims $(\mathrm{N}=221)$

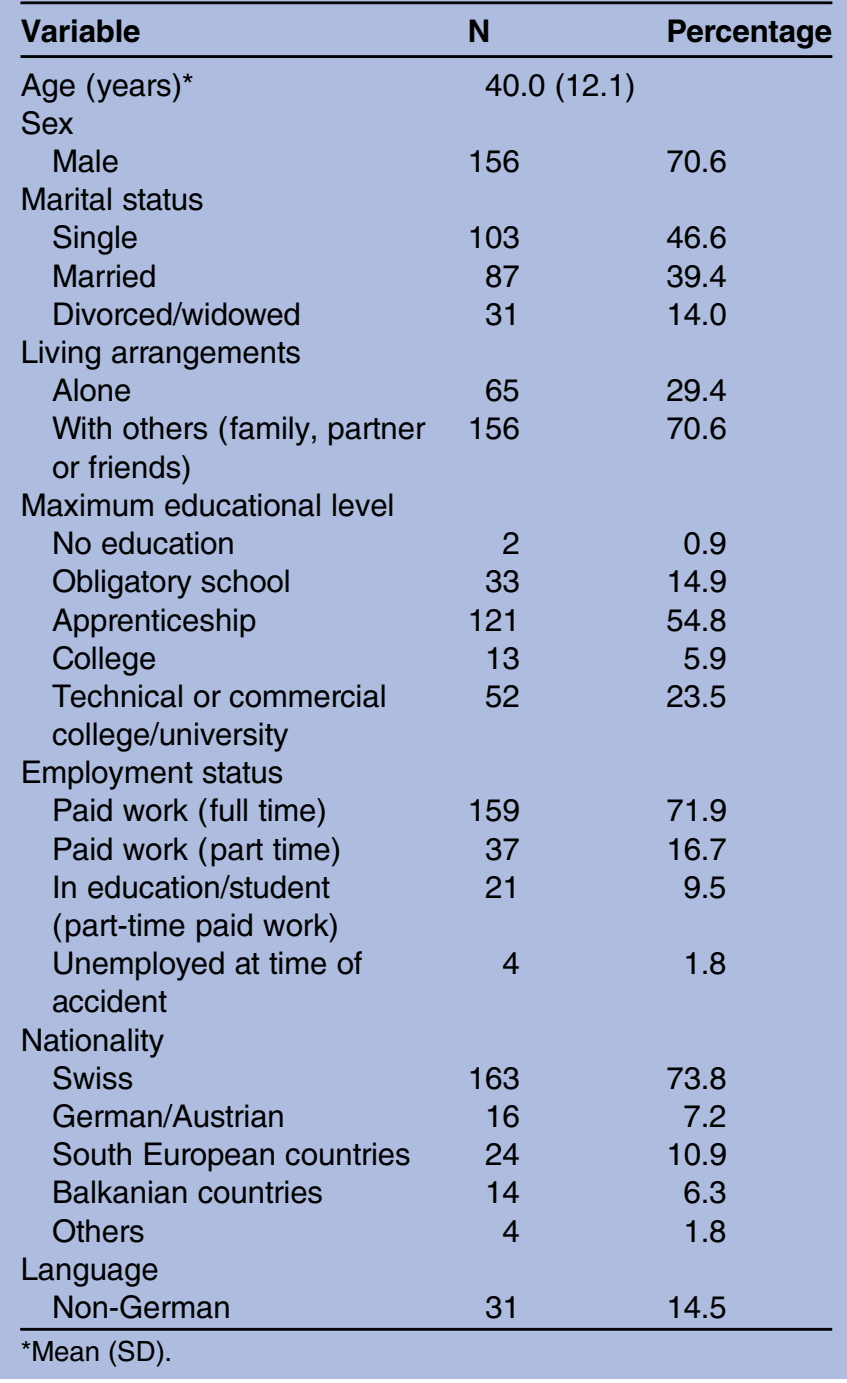

mental disorders did not differ significantly from the rest of the sample with regard to the number of sick leave days (mean difference $=2.7$ days, $95 \%$ CI -18.4 to 23.8, $\mathrm{t}=0.25, \mathrm{df}=219 ; \mathrm{p}=0.801$ ).

Bivariate correlations of all variables included in the regression analyses are presented in table 3 . The objective injury severity (ISS) and the patients' subjective appraisals of the accident severity were positively correlated. Subjective appraisals of the accident severity (but not the objective ISSs) were negatively related with selfrated coping abilities.

Time off work was significantly correlated with the injury severity (ISS), IES intrusion scores and the patients' own appraisals of their injury severity and their coping abilities. Finally, time off work was longer after workplace-related accidents and shorter after sports/ leisure-time accidents.

In a simultaneous regression analysis the variables injury severity (ISS), sex, age, type of accident (road traffic, workplace or leisure-time accidents) and IES intrusion were entered as potential predictors of time off work. Combined, these predictors explained $24.3 \%$ of the variance of time off work $(\mathrm{F}=9.75 ; \mathrm{df}=7,213$; $\mathrm{p}<0.001)$. When in a series of hierarchical regressions each of these predictors was examined when added last to this first set, ISS $(8.3 \%, \mathrm{~F}=23.38 ; \mathrm{df}=1,213 ; \mathrm{p}<0.001)$, type of accident $(7.6 \% ; \mathrm{F}$ change $=7.14 ; \mathrm{df}=3,213$; $\mathrm{p}<0.001)$ and IES intrusion added unique variance $(2 \%$; $\mathrm{F}=5.63 ; \mathrm{df}=1,213 ; \mathrm{p}=0.019)$. These five variables were then treated as the first set added in hierarchical regressions focusing on two additional predictors, patients' appraisals of accident severity and of their coping abilities. These two variables were entered in the second step accounting for an additional $9.4 \%$ of the variance of the time off work 6 months postaccident ( $\mathrm{F}$ change $=15.04$; $\mathrm{df}=2,211 ; \mathrm{p}<0.001)$. Self-reported appraisal of accident severity added $6 \%(\mathrm{~F}$ change $=18.14 ; \mathrm{df}=1,212 ; \mathrm{p}<0.001)$ and self-reported appraisal of their coping abilities added $4.7 \%$ ( $\mathrm{F}$ change $=14.17 ; \mathrm{df}=1,212 ; \mathrm{p}<0.001)$. Finally, each of the seven predictors in table 4 was evaluated for unique variance contributed with the other six predictors already in the model. The severity of the injury (ISS), type of accident and the two appraisals variables remained significant, whereas age, gender and IES intrusion did not contribute significantly to the prediction of time off work.

In order to visualise the effects of appraisals on sick leave days, the sample was divided into four groups based on median-splits in the two variables, appraisal of accident severity and appraisal of coping abilities (figure 1). The median was 4 Likert points in the subjective accident

Table 2 Injury-related characteristics of injured accident victims $(\mathrm{N}=221)$

\begin{tabular}{|c|c|c|c|c|}
\hline Variable & Mean & SD & Minimum & Maximum \\
\hline Injury Severity Score & 12.1 & 10.1 & 1 & 66 \\
\hline Glasgow Coma Scale & 14.8 & 0.7 & 9 & 15 \\
\hline Length of stay (days) at the intensive care unit ${ }^{*}$ & 4.0 & 3.7 & 1 & 19 \\
\hline Length of stay (days) at the University Hospitaltł & 15.8 & 16.9 & 2 & 110 \\
\hline Length of stay (days) at the University Hospital and rehabilitation†‡ & 23.1 & 28.8 & 2 & 163 \\
\hline Time off work at T2 $\ddagger$ & 95.7 & 58.1 & 6 & 183 \\
\hline
\end{tabular}

${ }^{*} n=41$ cases at the intensive care unit. 
Table 3 Bivariate correlations (Pearson's correlation coefficients) between potential predictor variables (assessed 3-28 days after the accident) to each other and to the dependent variable time off work due to the unintentional injury (assessed 6 months after the accident; $\mathrm{N}=221$ )

\begin{tabular}{|c|c|c|c|c|c|c|c|c|c|}
\hline Variable & TOW & ISS & Sext & Age & TRAFF & WORK & SPORT & IESIN & AAS \\
\hline ISS & $0.35^{\star \star \star}$ & & & & & & & & \\
\hline Sex & -0.08 & $-0.17^{\star}$ & & & & & & & \\
\hline Age & 0.09 & $-0.19^{\star *}$ & 0.09 & & & & & & \\
\hline TRAFF & -0.01 & $0.27^{\star \star \star}$ & 0.01 & $-0.22^{\star \star \star}$ & & & & & \\
\hline WORK & $0.23^{\star * \star}$ & 0.01 & $-0.23^{\star \star \star}$ & $0.16^{\star}$ & $-0.21^{* *}$ & & & & \\
\hline SPORT & $-0.28^{\star \star \star}$ & $-0.21^{\star \star}$ & 0.04 & -0.06 & $-0.26^{\star * *}$ & $-0.23^{\star \star \star}$ & & & \\
\hline IESIN & $0.21^{\star \star}$ & $0.23^{\star \star \star}$ & 0.11 & 0.03 & 0.10 & -0.08 & -0.04 & & \\
\hline AAS & $0.40^{\star \star \star}$ & $0.34^{\star \star \star}$ & -0.06 & -0.02 & 0.12 & 0.13 & -0.13 & $0.27^{\star \star \star *}$ & \\
\hline ACA & $-0.29^{\star \star \star}$ & -0.08 & -0.01 & -0.01 & -0.01 & -0.09 & 0.06 & $-0.15^{\star}$ & $-0.19^{\star \star}$ \\
\hline
\end{tabular}

${ }^{*} \mathrm{p} \leq 0.05,{ }^{* *} \mathrm{p} \leq 0.01,{ }^{* * *} \mathrm{p} \leq 0.001$.

†Sex: $1=$ male, $2=$ female.

AAS, appraisal of accident severity; ACA, appraisal of coping abilities; IESIN, Impact of Event Scale-intrusion subscale; ISS, Injury Severity Score; SPORT, sports or leisure accident; TOW, time off work (days) due to the unintentional injury; TRAFF, traffic accident; WORK, workplace accident.

severity scale, and 5 Likert points in the self-rated coping abilities scale. The patients with values equal or higher than the median were grouped as 'higher' in the respective characteristic and the patients with values lower than the median were grouped as 'lower' concerning the subjective accident severity or self-rated coping abilities. Regarding the two groups of particular interest, namely the patients who assessed the accident severity as higher and their coping abilities as lower compared with the patients who estimated the accident severity as lower and their coping abilities as higher, there were twice as many sick leave days for the former group (mean difference= -68.1 days, $95 \%$ CI -85.7 to $-50.5, \mathrm{t}=-7.67, \mathrm{df}=124$; $\mathrm{p}<0.001)$.

\section{DISCUSSION}

How patients perceive the severity of their accident and their ability to cope with the resulting injury and its

\begin{tabular}{|c|c|c|c|}
\hline Predictor variable & $\boldsymbol{\beta}$ & $95 \% \mathrm{Cl}$ for $\boldsymbol{\beta}$ & p Value \\
\hline Injury Severity Score & 0.25 & 0.12 to 0.37 & $<0.001$ \\
\hline Female gender & -0.01 & -0.13 to 0.11 & 0.893 \\
\hline Age & 0.09 & -0.03 to 0.21 & 0.140 \\
\hline \multicolumn{4}{|l|}{ Type of accident } \\
\hline Traffic & -0.12 & -0.24 to 0.01 & 0.062 \\
\hline Workplace & 0.10 & -0.02 to 0.23 & 0.112 \\
\hline Sports/leisure & -0.18 & -0.31 to -0.06 & 0.003 \\
\hline IES intrusion subscale & 0.07 & -0.05 to 0.19 & 0.261 \\
\hline $\begin{array}{l}\text { Appraisal of accident } \\
\text { severity }\end{array}$ & 0.24 & 0.12 to 0.36 & $<0.001$ \\
\hline $\begin{array}{l}\text { Appraisal of coping } \\
\text { abilities }\end{array}$ & -0.19 & -0.31 to -0.08 & 0.001 \\
\hline
\end{tabular}

Multiple regression: $\mathrm{N}=221, \mathrm{R}=0.58, \mathrm{R}^{2}=0.34, \mathrm{~F}=11.93 ; \mathrm{df}=9,211$; $\mathrm{p}<0.001$.

IES, Impact of Event Scale. job-related consequences are crucial predictors for return to work after unintentional injuries which lead to hospital admission. The current study demonstrated that the patients' own appraisals of the severity of their accident and of their coping resources predict time off work after accidents leading to hospital admission beyond the impact of the objective injury severity (ISS).

Some limitations of this study have to be addressed. To enable the findings from this current study to be better generalised to all hospitalised accident victims, we applied a very few exclusion criteria. For example, we did not exclude patients with pre-existing somatic and psychiatric morbidity or non-ICU patients. While this may have strengthened the external validity of our

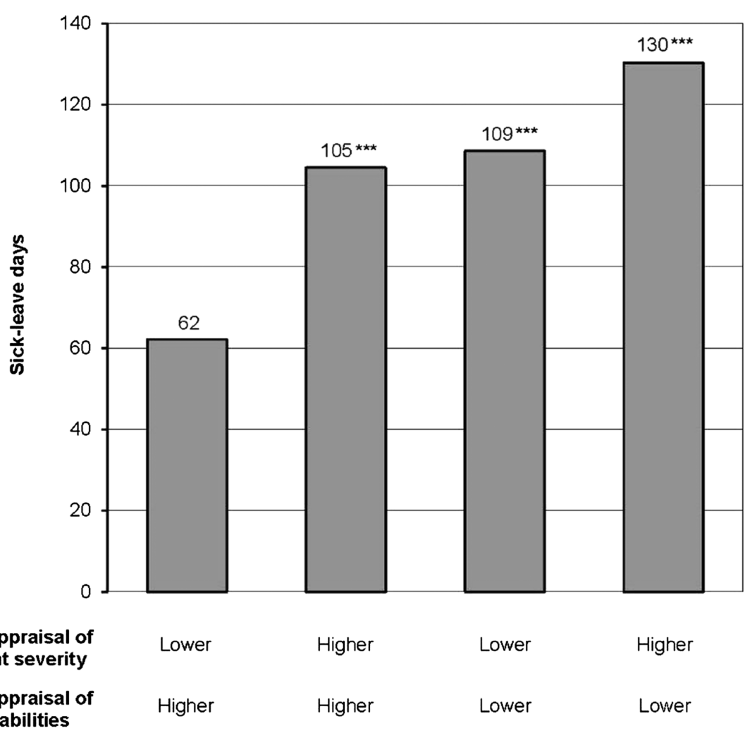

Figure 1 Sick leave days of accident victims depending on appraisals of injury severity and coping abilities $(\mathrm{N}=221$, $\mathrm{n}=31-78$ /group). Comparison of the group "lower appraisal of injury severity and higher appraisal of coping abilities" with the three other groups: ${ }^{\star \star *} p \leq 0.001$. 
findings, factors other than the unintentional injury might have influenced outcomes. By including patients with pre-existing somatic and psychiatric morbidity we possibly included patients who were at higher risk for sick leave following unintentional injury. However, patients suffering from pre-existing mental disorders did not differ from other patients with regard to the number of sick leave days. The inclusion criterion of being hospitalised for at least $32 \mathrm{~h}$ including two consecutive nights may limit the generalisability of the study's findings, but guaranteed that all patients in the sample were really hospitalised and not only received an overnight treatment in the emergency room (which formally is an instance of hospitalisation but in fact is an outpatient treatment). Another factor that may affect return to work is compensation eligibility. ${ }^{10}{ }^{19}$ In Switzerland all inhabitants receive compensation in the case of work incapacity or disability independent of the type of accident. For employees there is a mandatory accident insurance that covers work-related and non-work-related injuries due to accidents Thus, it is unlikely that different compensation rules related to different types of accidents biased our results. Nevertheless, the very generous compensation system in Switzerland may limit the generalisability of our findings to other countries with other or less generous compensation systems. Furthermore, there were $68(23.5 \%)$ dropouts from $\mathrm{T} 1$ to $\mathrm{T} 2$ in our study. It is unlikely that these dropouts affected the results substantially as they did not differ significantly from the final sample. Finally, the number of days off work was assessed by means of selfreport by the patients. Strict data privacy protection laws in Switzerland prevent the use of health insurance companies' data for the purpose of research projects. Such data would have been more reliable.

The relevance of psychosocial and subjective factors for a successful return to work after accidents has been increasingly recognised in the literature. ${ }^{7} \begin{array}{lllll}11 & 20 & 26 & 27 & 35\end{array}$ The total amount of explained variance in the present study was moderate $\left(\mathrm{R}^{2}=0.34\right)$ but within the range of comparable studies. ${ }^{8}{ }^{912-14} 26$ Nevertheless, this suggests that other factors than the ones we examined are also important regarding return to work. Extending the findings from previous studies among severely injured accident victims, ${ }^{7} 8{ }^{13}$ the current study confirmed the predictive value of patients' subjective appraisals of the accident severity for the whole spectrum of patients admitted to hospitals with unintentional injuries. In contrast to our previous study in severely injured accident victims who were hospitalised at the ICU, ${ }^{13}$ the completely independent sample of the current study included all unintentional injuries leading to hospital admission, with only $18.6 \%$ of the patients requiring ICU treatment. In an effort to enable the findings from this current study to be better generalised, unlike in our previous study with another sample, ${ }^{8}{ }^{13}$ we did not exclude foreign language patients and patients with preexisting somatic illnesses and mental disorders. In some cases, these particular patients may be less well socially integrated or have greater difficulties dealing with the consequences of unintentional injuries, both being risk factors for work disability. In our heterogeneous sample including moderately injured and foreign language accident victims with pre-existing somatic and psychiatric morbidity, the subjectively experienced accident severity predicted time off work after the accidents to the same degree as the objective injury severity (regression weights: $\beta=0.24$ vs 0.25 ). The role of the objective injury severity regarding time off work after unintentional injuries is ambiguous. In keeping with some previous studies, ${ }^{2} 78$ we found the more severe injuries to be related to more days off work. However, some other studies could not find that association. ${ }^{9} 1112 \quad 36$ These inconsistent findings might be explained by the different ranges of injury severities and by the different follow-up intervals used in different studies. The wider the range of injury severities in a study, the higher the chance that the severity of the physical impairment predicts subsequent time off work. The more time that has elapsed since the accident, the less impact the objective injury severity is expected to have on time off work. The physical condition may play a more important role immediately following the accident because hospitalisation and rehabilitation directly contribute to the time off work, whereas in the longer term, other factors might gain in importance regarding sick leave. In our previous study among severely injured accident victims, the objective injury severity predicted time off work during the first year after the accident but was no longer predictive for the number of days off work at the 3-year follow-up. ${ }^{8} 13$ In a longer term perspective, factors other than the objective physical impairment, for example, psychosocial or subjective factors, might gain in importance regarding return to work.

Concerning subjective factors predicting return to work, the patients' appraisals of the ability to cope with the unintentional injury and its job-related consequences turned out to be another important predictor of sick leave after hospital admissions due to unintentional, accident-related injuries. The more coping resources patients perceived themselves to have at their disposal immediately after the accident, the better his or her chances for vocational rehabilitation actually were. The significance of subjectively perceived coping abilities for return to work has already been found in earlier studies. ${ }^{8} 12$ 13 The predictive value of the patients' appraisals of the accident severity and of the coping abilities regarding time off work after unintentional injuries may be explained by Lazarus's ${ }^{37}$ theories on stress, appraisal and coping. ${ }^{38}$ Lazarus emphasised the significance of primary and secondary appraisal of a stressful situation or event. In a primary appraisal, the same situation can be judged as harmful, as a threat or as a challenge by different individuals. In a secondary appraisal, the individual judges the ability to cope with the situation depending on his or her individual coping 
strategies. If a stressful situation is appraised as controllable by action, problem-focused coping will predominate. In a situation viewed as refractory to change, however, emotion-focused coping is more likely to predominate. Among accident victims, these two steps of appraisals seem to be related. In our sample, the more threatening the patients judged their accident to have been, the fewer resources they perceived themselves to have at their disposal for coping with the unintentional injury and its job-related consequences. However, the subjective appraisal of the coping abilities was not correlated with the objective injury severity. This further emphasises the importance of considering not only the patient's objective injury severity but also their own appraisal of the accident severity and the coping abilities when predicting the chances of return to work. Coping with stressful events is increasingly viewed as a process rather than an inert (personality) style. If coping is open to change over time in accordance with the situational context, ${ }^{30} 37$ this may be promising for preventive and therapeutic interventions.

\section{CONCLUSION}

A patient's own appraisal of the severity of his/her accident and of his/her ability to cope with the unintentional injury and its job-related consequences is highly relevant for return to work after accidents leading to hospital admission. Both subjective appraisals predict time off work beyond the impact of the objective injury severity in the whole spectrum of patients hospitalised due to unintentional injuries.

In Western countries the quality of surgical care of accident victims has reached a high standard. In patients hospitalised with unintentional injuries, even where acute surgical care is inevitable, from a less immediate standpoint and bearing in mind future rehabilitation, a patient's subjective assessment seems to gain in importance where his/her recovery is concerned. It appears that relevant prognostic information regarding return to work can be obtained by asking the patient two simple questions:

1. How severe do you think your accident was?

2. How well do you think you will be able to handle the consequences of the accident with regard to return to work?

Any comprehensive treatment following unintentional injuries should routinely be accompanied by a brief psychosocial assessment and should include information and practical advice.

Contributors US and HM designed the study. HM, SH-B and JF-P were involved in the data collection. HM performed the statistical analyses. UH, HM, NS and US were involved in the interpretation of the data. NS, UH and HM drafted the manuscript. US reviewed the manuscript several times. All authors have read and approved the final version of the manuscript.

Funding This study was supported by the Swiss National Science Foundation (32-053736.98).

Competing interests None.
Ethics approval Ethical approval was granted by the Ethics Committee of the Canton of Zurich (Switzerland).

Provenance and peer review Not commissioned; externally peer reviewed.

Data sharing statement No additional data are available.

Open Access This is an Open Access article distributed in accordance with the Creative Commons Attribution Non Commercial (CC BY-NC 3.0) license, which permits others to distribute, remix, adapt, build upon this work noncommercially, and license their derivative works on different terms, provided the original work is properly cited and the use is non-commercial. See: http:// creativecommons.org/licenses/by-nc/3.0/

\section{REFERENCES}

1. Bauer R, Steiner M. Injuries in the European Union. Statistics summary 2005-2007. Vienna: KfV, Austrian Road Safety Board, 2009.

2. MacKenzie EJ, Morris JA Jr, Jurkovich GJ, et al. Return to work following injury: the role of economic, social, and job-related factors. Am J Public Health 1998;88:1630-7.

3. Leigh JP, Markowitz SB, Fahs M, et al. Occupational injury and illness in the United States. Estimates of costs, morbidity, and mortality. Arch Intern Med 1997;157:1557-68.

4. Ebel BE, Mack C, Diehr P, et al. Lost working days, productivity, and restraint use among occupants of motor vehicles that crashed in the United States. Inj Prev 2004;10:314-19.

5. Loisel P, Anema JR. eds. Handbook of work disability. Prevention and management. New York, NY: Springer, 2013.

6. MacKenzie EJ, Shapiro S, Smith RT, et al. Factors influencing return to work following hospitalization for traumatic injury. Am J Public Health 1987;77:329-34.

7. Soberg HL, Finset A, Bautz-Holter E, et al. Return to work after severe multiple injuries: a multidimensional approach on status 1 and 2 years postinjury. J Trauma 2007;62:471-81.

8. Schnyder U, Moergeli $\mathrm{H}$, Klaghofer R, et al. Does patient cognition predict time off from work after life-threatening accidents? Am J Psychiatry 2003;160:2025-31.

9. Michaels AJ, Michaels $\mathrm{CE}$, Moon $\mathrm{CH}$, et al. Psychosocial factors limit outcomes after trauma. J Trauma 1998;44:644-8.

10. Zelle BA, Panzica M, Vogt MT, et al. Influence of workers' compensation eligibility upon functional recovery 10 to 28 years after polytrauma. Am J Surg 2005;190:30-6.

11. Davydow DS, Zatzick DF, Rivara FP, et al. Predictors of posttraumatic stress disorder and return to usual major activity in traumatically injured intensive care unit survivors. Gen Hosp Psychiatry 2009;31:428-35.

12. Lange $C$, Burgmer $M$, Braunheim $M$, et al. Prospective analysis of factors associated with work reentry in patients with accident-related injuries. J Occup Rehabil 2007;17:1-10.

13. Hepp U, Moergeli H, Buchi S, et al. The long-term prediction of return to work following serious accidental injuries: a follow up study. BMC Psychiatry 2011;11:53.

14. Lilley R, Davie G, Ameratunga $S$, et al. Factors predicting work status 3 months after injury: results from the Prospective Outcomes of Injury Study. BMJ Open 2012;2:e000400.

15. Hunter SJ, Shaha S, Flint D, et al. Predicting return to work. A long-term follow-up study of railroad workers after low back injuries. Spine 1998;23:2319-28.

16. Brewin CR, Robson MJ, Shapiro DA. Social and psychological determinants of recovery from industrial injuries. Injury 1983;14:451-5.

17. Andersson $\mathrm{AL}$, Bunketorp $\mathrm{O}$, Allebeck $\mathrm{P}$. High rates of psychosocial complications after road traffic injuries. Injury 1997;28:539-43.

18. Rusch MD, Dzwierzynski WW, Sanger JR, et al. Return to work outcomes after work-related hand trauma: the role of causal attributions. J Hand Surg 2003;28:673-7.

19. Hou WH, Sheu CF, Liang HW, et al. Trajectories and predictors of return to work after traumatic limb injury-a 2-year follow-up study. Scand J Work Environ Health 2012;38:456-66.

20. Mondloch MV, Cole DC, Frank JW. Does how you do depend on how you think you'll do? A systematic review of the evidence for a relation between patients' recovery expectations and health outcomes. CMAJ 2001;165:174-9.

21. Ozegovic D, Carroll LJ, Cassidy JD. What influences positive return to work expectation? Examining associated factors in a population-based cohort of whiplash-associated disorders. Spine (Phila Pa 1976) 2010;35:E708-13. 
22. Hansen A, Edlund C, Henningsson M. Factors relevant to a return to work: a multivariate approach. Work 2006;26:179-90.

23. Heijbel B, Josephson M, Jensen I, et al. Return to work expectation predicts work in chronic musculoskeletal and behavioral health disorders: prospective study with clinical implications. J Occup Rehabil 2006;16:173-84.

24. Lindell O, Johansson SE, Strender LE. Predictors of stable return-to-work in non-acute, non-specific spinal pain: low total prior sick-listing, high self prediction and young age. A two-year prospective cohort study. BMC Fam Pract 2010;11:53.

25. Lanes TC, Gauron EF, Spratt KF, et al. Long-term follow-up of patients with chronic back pain treated in a multidisciplinary rehabilitation program. Spine 1995;20:801-6.

26. Toien K, Skogstad L, Ekeberg O, et al. Prevalence and predictors of return to work in hospitalised trauma patients during the first year after discharge: a prospective cohort study. Injury 2012; 43:1606-13.

27. Clay FJ, Fitzharris M, Kerr E, et al. The association of social functioning, social relationships and the receipt of compensation with time to return to work following unintentional injuries to Victorian workers. J Occup Rehabil 2012;22:363-75.

28. Baker SP, O'Neill B. The injury severity score: an update. J Trauma 1976;16:882-5.
29. Teasdale G, Jennett B. Assessment of coma and impaired consciousness. A practical scale. Lancet 1974;2:81-4.

30. Hepp U, Moergeli $\mathrm{H}$, Buchi S, et al. Coping with serious accidental injury: a one-year follow-up study. Psychother Psychosom 2005;74:379-86.

31. Horowitz M, Wilner N, Alvarez W. Impact of Event Scale: a measure of subjective stress. Psychosom Med 1979;41:209-18.

32. Spitzer RL, Williams JB, Kroenke $\mathrm{K}$, et al. Utility of a new procedure for diagnosing mental disorders in primary care. The PRIME-MD 1000 study. JAMA 1994;272:1749-56.

33. Sundin EC, Horowitz MJ. Horowitz's Impact of Event Scale evaluation of 20 years of use. Psychosom Med 2003;65:870-6.

34. Schnyder U, Wittmann L, Friedrich-Perez J, et al. Posttraumatic stress disorder following accidental injury: rule or exception in Switzerland? Psychother Psychosom 2008;77:111-18.

35. MacEachen E, Clarke J, Franche RL, et al. Systematic review of the qualitative literature on return to work after injury. Scand J Work Environ Health 2006;32:257-69.

36. Post RB, van der Sluis CK, Ten Duis HJ. Return to work and quality of life in severely injured patients. Disabil Rehabil 2006;28:1399-404.

37. Lazarus RS. Coping theory and research: past, present, and future. Psychosom Med 1993;55:234-47.

38. Lazarus RS, Folkman S. Stress, appraisal and coping. New York: Springer, 1984. 